\title{
Climatological features of blocking anticyclones: a study of Northern Hemisphere CCM1 model blocking events in present-day and double $\mathrm{CO}_{2}$ concentration atmospheres
}

\author{
A. R. Lupo ${ }^{1, *}$, R. J. Oglesby ${ }^{1}$, I. I. Mokhov $^{2}$ \\ ${ }^{1}$ Department of Earth and Atmospheric Science, Purdue University, West Lafayette, IN 47907-1397, USA \\ ${ }^{2}$ Institute of Atmospheric Physics, Russian Academy of Sciences, 3 Pyzhevsky, Moscow 109017, Russia
}

Received: 8 May 1995/Accepted: 20 September 1996

\begin{abstract}
Using output made with the National Center for Atmospheric Research (NCAR) Community Climate Model Version 1 (CCM1), the characteristics of blocking events over the Northern Hemisphere in a ten-year present day control simulation with a $\mathrm{CO}_{2}$ concentration of $330 \mathrm{ppm}$ were compared to those in a previously analyzed observational three-year climatology. The characteristics of blocking events in a double present-day $\mathrm{CO}_{2}$ concentration simulation were then compared to those in the control simulation in order to evaluate how these characteristics might change in an increased $\mathrm{CO}_{2}$ atmosphere. The results demonstrated that in the Northern Hemisphere the CCM1 correctly simulated many characteristics of blocking events such as average annual number of occurrences, annual variations is size and intensity, and preferred formation regions. A more detailed analysis (i.e., by region and season) revealed some differences between the CCM1 and observed blocking events for characteristics such as mean frequency of occurrence, intensity, size and duration. In addition, the model failed to capture adequately the occurrence of blocking events over the western Asian continent. A comparison of the double $\mathrm{CO}_{2}$ concentration run to the control showed that, in general, blocking events were more persistent and weaker, but of similar size in the increased $\mathrm{CO}_{2}$ atmosphere. Also, some statistically significant regional and seasonally dependent changes were found in the frequency of occurrence, duration, and intensity. Finally, a correlation between block size and intensity, significant at the $99 \%$ confidence level, was found in each climatology. This result is similar to a correlation found in the analysis of observations.
\end{abstract}

\section{Introduction}

General circulation models (GCMs) have become useful in diagnosing and understanding the processes associated

Correspondence to: A. R. Lupo

* Present address: Department of Earth and Atmospheric Science, ES-226, State University of New York at Albany/Suny, Albany, NY 12222, USA with large-scale phenomena such as blocking anticyclones. In the Northern Hemisphere, standing eddies are responsible for a significant portion of the total poleward heat and momentum transports (e.g., Wiin-Neilsen 1986). Blocking anticyclones may be included as an example of such a phenomenon, at least in a climatological sense. Therefore, it is desirable to determine whether or not a general circulation model can sufficiently reproduce the occurrence of such phenomena in a climatological sense, and Tibaldi (1993) and Tibaldi et al. (1994) suggest that blocking diagnostics can be used to evaluate the performance of GCMs. This is also of interest because blocking anticyclones link both the synoptic and planetary scales. A number of recent diagnostic and observational studies have examined blocking anticyclones and their relationship to the synoptic scale (e.g., Colucci 1985, 1987), the planetary scale (e.g., Hansen 1986; Lejenas and Madden 1992; Mokhov et al. 1994), and their interactions (e.g., Tsou and Smith 1990; Lupo and Smith 1995b). Blocking anticyclone events can also be associated with recurrent subseasonal features such as "Indian Summer" in the fall (Agayan and Mokhov 1989; Mokhov 1993). In addition, there has recently been a great interest in using GCMs to determine what future climates may look like in the face of anthropogenically increased $\mathrm{CO}_{2}$ concentrations (e.g., Oglesby and Saltzman 1992; Held 1993; and many others).

This study uses the National Center for Atmospheric Research's (NCAR) Community Climate Model version 1 (CCM1). A previous version of the CCM model (CCM0B) (R15 truncation) was used by Bates and Meehl (1986) to examine global $500 \mathrm{mb}$ height statistics and develop a climatology of blocking anticyclones. Their study showed that CCMOB did well in capturing the large-scale features of the general circulation in both the Northern and Southern Hemispheres, especially during the winter season. The model also did well in representing the annual occurrence of blocking anticyclones, however, there were some important regional and seasonal differences between observations and the model regarding the location and occurrence of blocking events. Bates and Meehl also demonstrated that, in the Northern Hemisphere, the frequency 
of blocking anticyclone occurrence would not change significantly if the concentration of carbon dioxide $\left(\mathrm{CO}_{2}\right)$ was doubled relative to present-day values, but that regions of the most frequent blocking occurrence may shift somewhat.

Any comparison between CCM1 and CCM0 should be prefaced by noting some relevant differences between the two models (Williamson et al. 1987). First, the improvements in the parametrizations and model physics in CCM1 leads to winters that were warmer than in CCM0 (CCM0 was systematically too cold at polar latitudes). The colder winter climate in CCM0 resulted in sea-ice margins being located farther equatorward than observed, especially for the North Atlantic (Bates and Meehl 1986). Second, it is well known that CCM1 exhibits significantly less $500 \mathrm{hPa}$ geopotential height variances compared to CCM0 or to observed height variances (e.g., Hansen and Sutera 1993a). This difference between CCM1 and CCM0 or observations is a particular problem within the storm track regions and over the eastern Northern Hemisphere oceans, which are the typical blocking regions (e.g., Hansen and Sutera 1993a). Therefore, we might expect that any climatology developed from CCM1 would have fewer, weaker, or less persistent blocking events than a similar climatology derived from CCM0 or observational data. Such a comparison may also yield any combination, or all, of these changes in blocking anticyclone characteristics. However, this may not be true for every particular region or season. For example, a CCM1 perpetual January simulation showed stronger time-mean stationary waves than in CCM0 or as observed over the eastern Pacific ocean basin (Hansen and Sutera 1993a), and could presumably predispose the flow in that particular region and season to blocking (A. Hansen personal communication).

The primary objective of this study is to develop a climatology for Northern Hemisphere blocking anticyclones using simulations made with CCM1. These include a present-day (control) simulation, and a double present-day carbon-dioxide $\left(2 \times \mathrm{CO}_{2}\right)$ concentration simulation. Climatologies from both simulations were developed using the methodology of Lupo and Smith (1995a) (hereafter LS95). The climatology of the present-day simulation was also compared to the results of LS95, who obtained an observational climatology of blocking anticyclones that was shown to have results that were qualitatively similar to those of much longer climatological studies, in particular those in Triedl et al. (1981) and Lejenas and Okland (1983). The double $\mathrm{CO}_{2}$ concentration results are compared to the control simulation results to determine how increased $\mathrm{CO}_{2}$ concentrations may affect the characteristics of blocking anticyclones in future climates. Finally, while the methodologies used are very different, our experimental strategy is similar to that of Bates and Meehl (1986). Therefore, the overall results of this study will be compared to theirs to determine if two different methodologies will yield similar conclusions about the model's performance and if improvements to the CCM model (CCM1 versus CCMOB) results in a more faithful climatology of blocking anticyclones when compared to observations.

\section{Data and methodology}

\subsection{Data}

The data used in this study are latitude longitude gridded data fields derived from output generated by the NCAR CCM1 model. The version of CCM1 used to generate the data is a global pseudo-spectral (R15), primitive equation general circulation model (GCM) with a horizontal resolution equivalent to a $4.5^{\circ}$ latitude by $7.5^{\circ}$ longitude grid and has $12 \sigma$-surface layers in the vertical (Phillips 1957). This version of the CCM was chosen since, to our knowledge, no comparable blocking climatology using CCM1 exists, the model runs described later were readily available (no equivalent model runs are yet available from (CCM2), and the truncation (R15) is the same as that of the CCMOB model used in the Bates and Meehl (1986) study. More importantly, however, Chen and Tribbia (1993) demonstrate that the stationary long waves in the Northern Hemisphere are more faithfully represented by the $\mathrm{R} 15$ version of CCM1 than at higher resolution, such as the T31 and T42 version. This is important, at least in order for the model to generate blocking anticyclones in the right locations, since the occurrence of blocking seems to favor regions at the end of the climatological storm tracks, which are "anchored" by the standing long wave pattern in the Northern Hemisphere (e.g., Mak and Cai 1989). The CCM model can be used to calculate atmospheric temperatures, horizontal wind components, humidity and mass distributions as prognostic variables computed 48 times daily, but output only twice daily. Other variables used to derive these quantities (or obtainable from them) are determined diagnostically. Williamson et al. (1987) provide a more detailed description of the model, and Blackmon (1986) describes the development of the model.

In order to calculate sea surface temperatures (SSTs), CCM1 was coupled with a thermodynamic slab-ocean and sea ice model originally formulated by Semtner (1976) and adapted to the CCM1 model by Covey and Thompson (1989). While this type of ocean model does allow for atmosphere-ocean surface interactions (e.g., in the computation of water vapor), no dynamical aspects of the oceanic circulation such as heat and mass transports are included. The lack of dynamics means that features such as ocean currents (i.e., the Gulf Stream) and upwelling regions are not considered. These features can have a significant impact on SSTs, which is turn can directly or indirectly affect the favored climatological regions of cyclone formation and/or block formation, especially in the Atlantic. This point is important in interpreting the results of our study and more will be said about this relationship in the results section. The atmospheric carbon dioxide is prescribed in CCM1 and impacts on atmospheric radiation balance directly through the long-wave radiation computations using the model of Kiehl et al. (1987). Atmospheric $\mathrm{CO}_{2}$ also impacts on radiative balance via the short-wave radiation computations, but to a much smaller degree.

In this study, twice-daily (0000 UTC) model calculated geopotential heights at $500 \mathrm{hPa}$ are used for both the present-day control simulation (330 ppm) and the double 
$\mathrm{CO}_{2}(660 \mathrm{ppm})$ simulation. These data were generated by Oglesby and Saltzman (1992) for their study and obtained from the mass store facility at NCAR in Boulder, CO. It is important to note that both simulations were run using the same initial conditions as described by Oglesby and Saltzman (1992) except for $\mathrm{CO}_{2}$ concentration. Therefore, $\mathrm{CO}_{2}$ concentration in the second experiment was not gradually increased with time from $330 \mathrm{ppm}$ to $660 \mathrm{ppm}$, but was implemented instantaneously at the beginning of the run. The control model run was 20 years long and the double $\mathrm{CO}_{2}$ model run was 15 years long. An overlapping five-year period of model output (model years 11-15) was selected for study which allowed 10 years for model equilibration (more important for the double $\mathrm{CO}_{2}$ run, see Oglesby and Saltzman 1992). For a more detailed description of the strategies used in the model simulations, the experimentation, and data selection consult Oglesby and Saltzman (1992).

\subsection{Methodology}

The methodology is the same as that used in Lupo and Smith (1995a) and only a brief summary will be given here. The blocking criteria can be summarized as a combination of the Rex (1950) subjective definition, and the objective criterion of Lejenas and Okland (1983), with the exception that the minimum threshold for persistence was five days. This choice of a persistence threshold also differs from that of Bates and Meehl (1986), who used seven days in their definition. It should also be noted here that all comparisons of our results to those of Bates and Meehl are made by adjusting our (CCM1) and the LS95 summer and winter season definitions to fit those of Bates and Meehl (1986), removing all blocking cases lasting 5 or 6 days from the CCM1 and LS95 results, and normalizing totals in all three climatologies to annual averages. Additionally, Bates and Meehl used a "thresholding" methodology (i.e., a block is defined as a $500 \mathrm{hPa}$ height anomaly that exceeds a specified deviation from climatology for a specified length of time) following that of Shukla and Mo (1983), which is another objective technique considerably different from our methodology. Shukla and Mo (1983) also served as their comparison to observations.

Although long enough to provide a reasonable sample of blocking events, the ten-year (three-year) period chosen for study in this work (LS95) is short compared to some other climatological studies of blocking anticyclones. The relatively short period of observations was chosen by LS95 in order to make it practical to visually confirm the blocks identified in the twice-daily $500 \mathrm{hPa}$ height fields using the objective classification technique described therein (and briefly here), to calculate manually the blocking characteristics of each case, and to observe the relevant upstream cyclone and jet stream characteristics for each case. The ten-year (five-year) period chosen for the control (double $\mathrm{CO}_{2}$ ) simulation in this study were constrained by the length of the model runs (allowing for model equilibration). This procedure, therefore, combines some of the aspects and advantages of both subjective and objective blocking criteria that have been previously published in order create a uniform criterion that facilitates the compilation of all the blocking characteristics mentioned in this chapter.

The Lejenas-Okland $(L O)$ criterion (Lejenas and Okland, 1983) is defined as the difference between the $500 \mathrm{hPa}$ geopotential height at $40^{\circ} \mathrm{N}$ and $60^{\circ} \mathrm{N}$. These two latitudes were chosen based on the results of Triedl et al. (1981) who demonstrated that in the Northern Hemisphere, blocking anticyclones tend to be dipoles with a region of high pressure around $60^{\circ} \mathrm{N}$ and a region of low pressure around $40^{\circ} \mathrm{N}$. In this study the $L O$ index is given by;

$L O=Z 42.5^{\circ}-Z 60.0^{\circ}$,

where $Z$ represents the geopotential height at each given latitude. These latitudes were chosen since they are the ones output by CCM1 that are closest to the original formulation of the $L O$ index. Lejenas and Okland (1983) specify blocking to occur when the $L O$ index is negative over a sufficient longitudinal width. In order to meet this requirement, a second relationship that must be fulfilled was given as;

$\left(L O\left(1-10^{\circ}\right)+L O(1)+L O\left(1+10^{\circ}\right)\right) / 3<0$,

where 1 is the longitude. In using this index it is convenient to display $L O$ on a Hovmoller diagram (Hovmoller 1949), with longitude on the abscissa and time on the ordinate. However, as noted in LS95, small positive values of $L O$ can also indicate blocking. They found that a distinct signature can be imparted on a Hovmoller diagram by blocking events even when the location of the dipoles differed significantly from those in Eq. (1), and the values of $L O$ were small negative and/or positive values (generally with absolute values less than $50 \mathrm{~m}$ ).

Blocking anticyclone characteristics are also defined and classified by region and season in the same manner as in LS95. Among these characteristics are block intensity and size. Block intensity $(B I)$ is determined by normalizing the geopotential height value at the anticyclone center $\left(Z_{m}\right)$ through the use of the height contour that best represents the blocking anticyclone $\left(C_{r}\right)$. (The procedure for choosing this contour is also described in LS95.) Therefore, $B I$ is given by:

$B I=100.0^{*}\left[\left(Z_{m} / C_{r}\right)-1.0\right]$,

where 100.0 and 1.0 are constants chosen such that $B I$ varies between 1 and 10 on any given day. In order to minimize subjectivity, $C_{r}$ was determined in the following manner; (a) $C_{r}$ must represent the full wavelength between the trough lines of the upstream and downstream trough, (b) $C_{r}$ may not be a closed contour, and (c) $C_{r}$ is the middle contour of contours meeting the first two criteria. (If two contours satisfy (a) and (b), then the contour with the higher value is chosen.)

$Z_{m}$ represents the grid point with the maximum $500 \mathrm{hPa}$ geopotential height value in the closed blocking anticyclone region or on the ridge line associated with the block. Therefore, $B I$ is a measure of the average maximum height of the block over its lifetime normalized to adjust for daily and regional anomalies.

Each case is classified as strong $(B I>4.55)$, moderate $(4.55>B I>2.55)$, or weak $(B I<2.55)$, and the rationale 
for choosing these limits is discussed in more detail by LS95. The half-wavelength, or blocking anticyclone size, is defined as the distance $(\mathrm{km})$ between the upstream and downstream inflection points on $C_{r}$. As stated in LS95, these additional conditions for determining blocking characteristics provided a uniform set of guidelines for performing this study. One aspect of LS95 not examined here is the relationship of precursor cyclones to various characteristics of blocking anticyclones. This is because it is difficult to identify a specific cyclone event with confidence in a model with such coarse resolution (e.g., Stewart 1994; and many others).

Comparisons between the observational and model control climatologies and the control and $2 \times \mathrm{CO}_{2}$ model climatologies were made by examining the ten (model) and three-year (observed), annual, regional, and seasonal means and/or probability density functions (PDFs). As long as each set or subset contained a reasonable number of blocking events (e.g., 30 to 60 cases), any differences in the means or distributions were tested for significance at both the $95 \%$ and $99 \%$ confidence level. In cases where no meaningful statistical testing between two subsets could be performed, some of the seasonal means were still presented in order to provide the reader with a more detailed description of the results found in our study. Correlation coefficients were tested for significance using the $Z$-score test (Neter et al. 1988) and assuming the null-hypothesis, or that no a priori relationship between the two variables. PDFs were tested for goodness-of-fit versus a "standard" or "observed" (but unapproximated) distributions using the chi-square goodness-of-fit test (Neter et al. 1988). Lastly, comparisons of means were examined using a twosided "simple standardized test statistic" $\left(z^{*}\right)$ (Neter et al. 1988, pp. 310-366).

The Northern Hemisphere is divided into three regions. The Atlantic, Pacific and Continental regions are bounded in longitude by $80^{\circ} \mathrm{W}$ and $40^{\circ} \mathrm{E}, 140^{\circ} \mathrm{E}$ and $100^{\circ} \mathrm{W}$, and $40^{\circ} \mathrm{E}$ and $140^{\circ} \mathrm{E}$ (Eurasian continent) and $100^{\circ} \mathrm{W}$ and $80^{\circ} \mathrm{W}$ (North American continent), respectively. Each blocking event was then placed in one of these regions, based on its location (longitude) at onset. Blocking anticyclones were tracked by noting the longitude and latitude of the center point $Z$. The blocking year started on July 1 and ended June 30. This is consistent with the definition of other studies (e.g., Quiroz 1987) and is most appropriate considering the minimum of Northern Hemisphere blocking events occurring in the summertime. Finally, the winter, spring, summer, and fall seasons are defined as January to March, April to June, July to September, and October to December, respectively.

\section{Comparison of the control simulation to the observational climatology}

\subsection{The present-day $\mathrm{CO}_{2}$ concentration simulation versus LS95}

A comparison of preferred block formation regions for each aggregated sample (Fig. $1 \mathrm{a}, \mathrm{b}$ ) shows that the model performed generally well in capturing the broad formation region over the Pacific. Unlike the observational
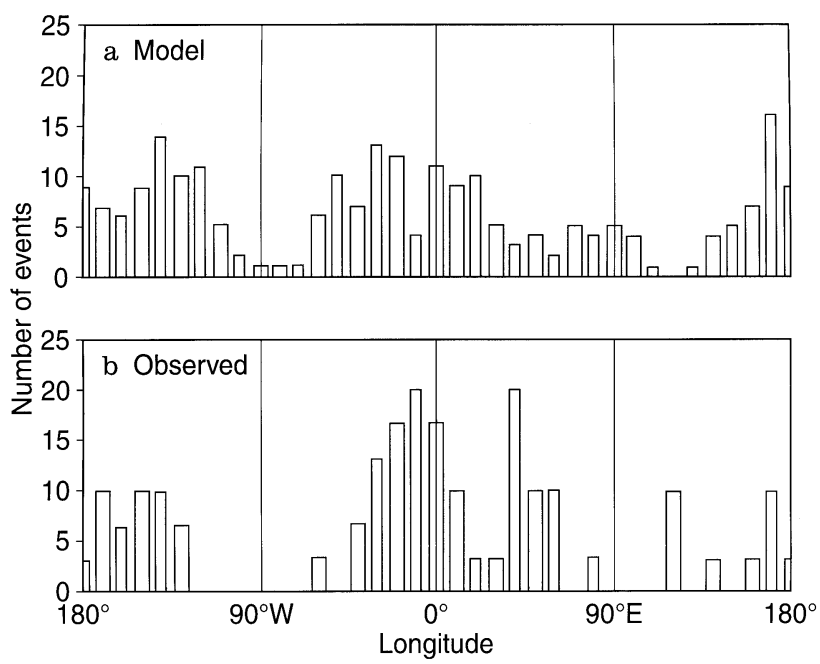

Fig. 1a, b. Number of blocking anticyclones forming in $10^{\circ}$ longitude basins per 10 year period in the Northern Hemisphere for a the control (330 ppm) simulation, and $\mathbf{b}$ the observed climatology (data taken from Lupo and Smith 1995a)

results, the model histogram exhibits a double maximum $\left(170^{\circ} \mathrm{E}\right.$ and near $\left.140^{\circ} \mathrm{W}\right)$ within the Pacific region. An examination of Fig. 1a also shows there are, in general, more blocking events in the Pacific region, unlike the observations (Fig. 1b). This suggests that there may be some differences in the dynamics between the model and real world in this region, and a full analysis of these differences is beyond the scope of this work. Comparing block formation histograms (Fig. 1) for the Atlantic region demonstrates that the model block formation region is shifted toward the west, with the frequency maximum about $20^{\circ}$ farther west than that of observed blocking events. This result may be at least partially due to the lack of a Gulf Stream in the slab-ocean model. Without the Gulf Stream, the associated lower atmospheric baroclinic zone east of North America would be weaker and confined to a smaller area off the east coast United States. The result is a weaker Atlantic storm track and subsequent placement of the storm track one model grid point south and west of observed storm tracks (e.g., Oglesby et al. 1989; Williamson and Williamson 1987). As shown by LS95a (and many others), blocking tends to occur just downstream of the storm tracks, and therefore, the westward placement of Atlantic blocking by the model is consistent with that of the model storm tracks. Finally, the model results fail to show the western Russian maximum in block formation found observationally (e.g., LS95). A possible reason for this failure is that the model does not adequately resolve the observed storm track region that stretches across the northern Mediterranean and into the Caspian Sea region (Whittaker and Horn 1982).

Figure 2 shows preferred block formation regions, as in Fig. 1, except the data is partitioned by season. For the summer season (Fig. 2a), the CCM1 model places the peak formation region over the western Pacific region (near $170^{\circ} \mathrm{E}$ ), which is about $40^{\circ}$ longitude west of the observed summer peak formation region (the central and eastern Pacific). CCM1 also featured peak formation regions near 


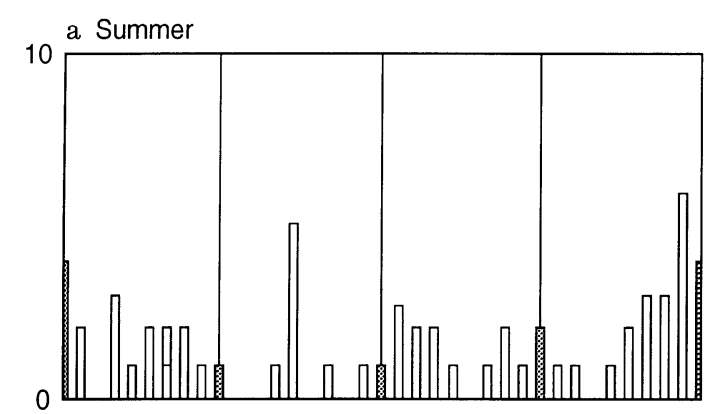

Model
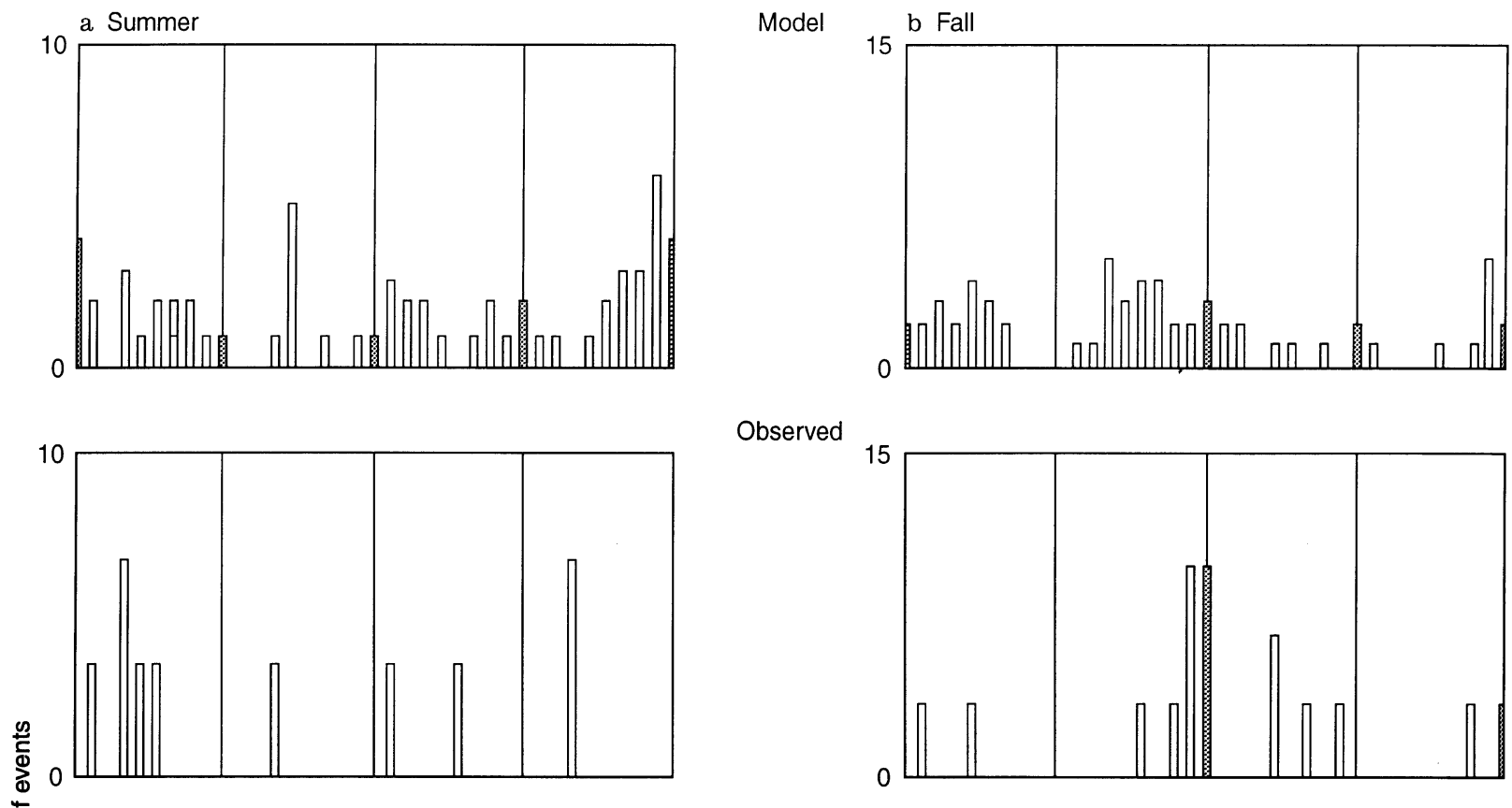

Observed
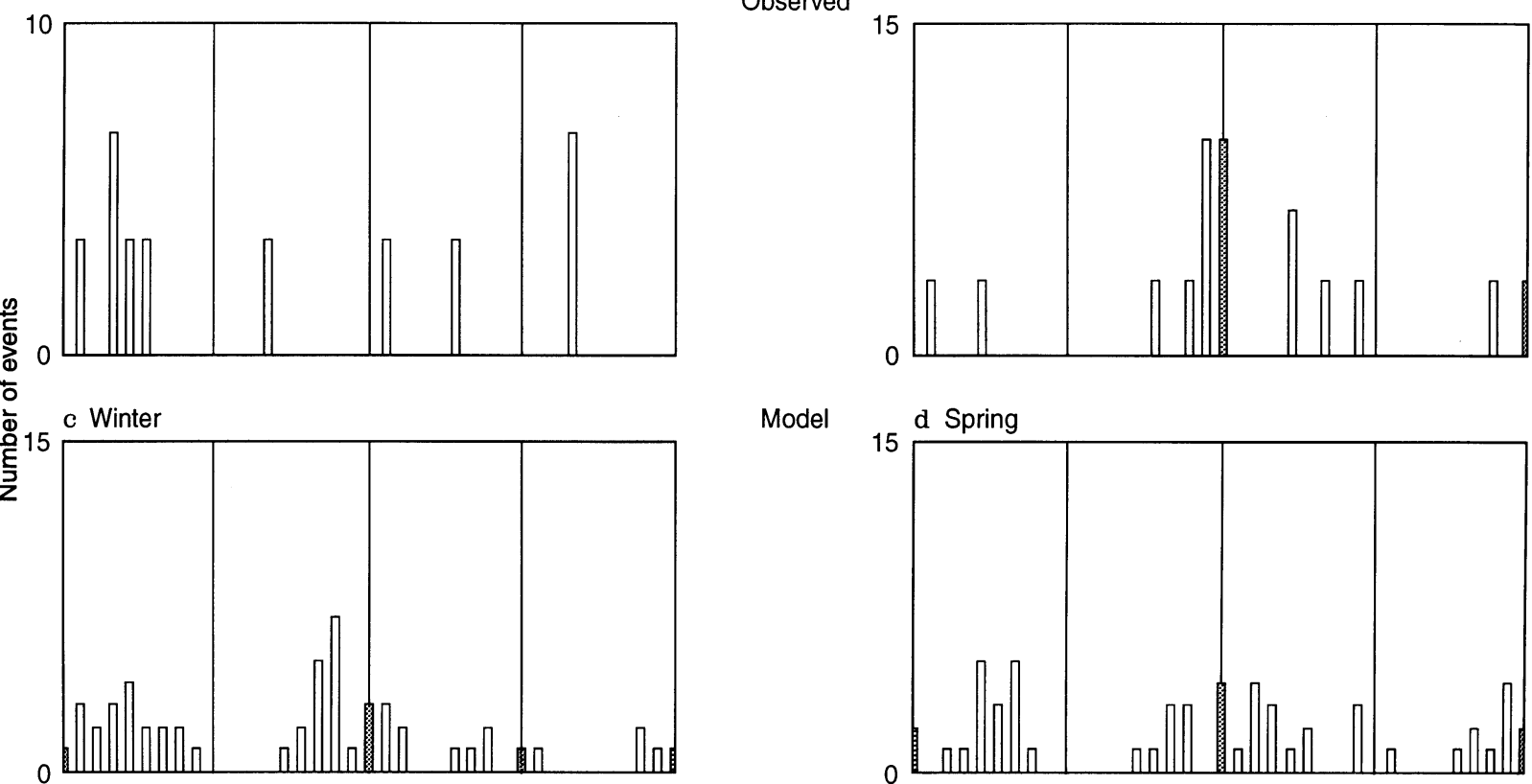

Model
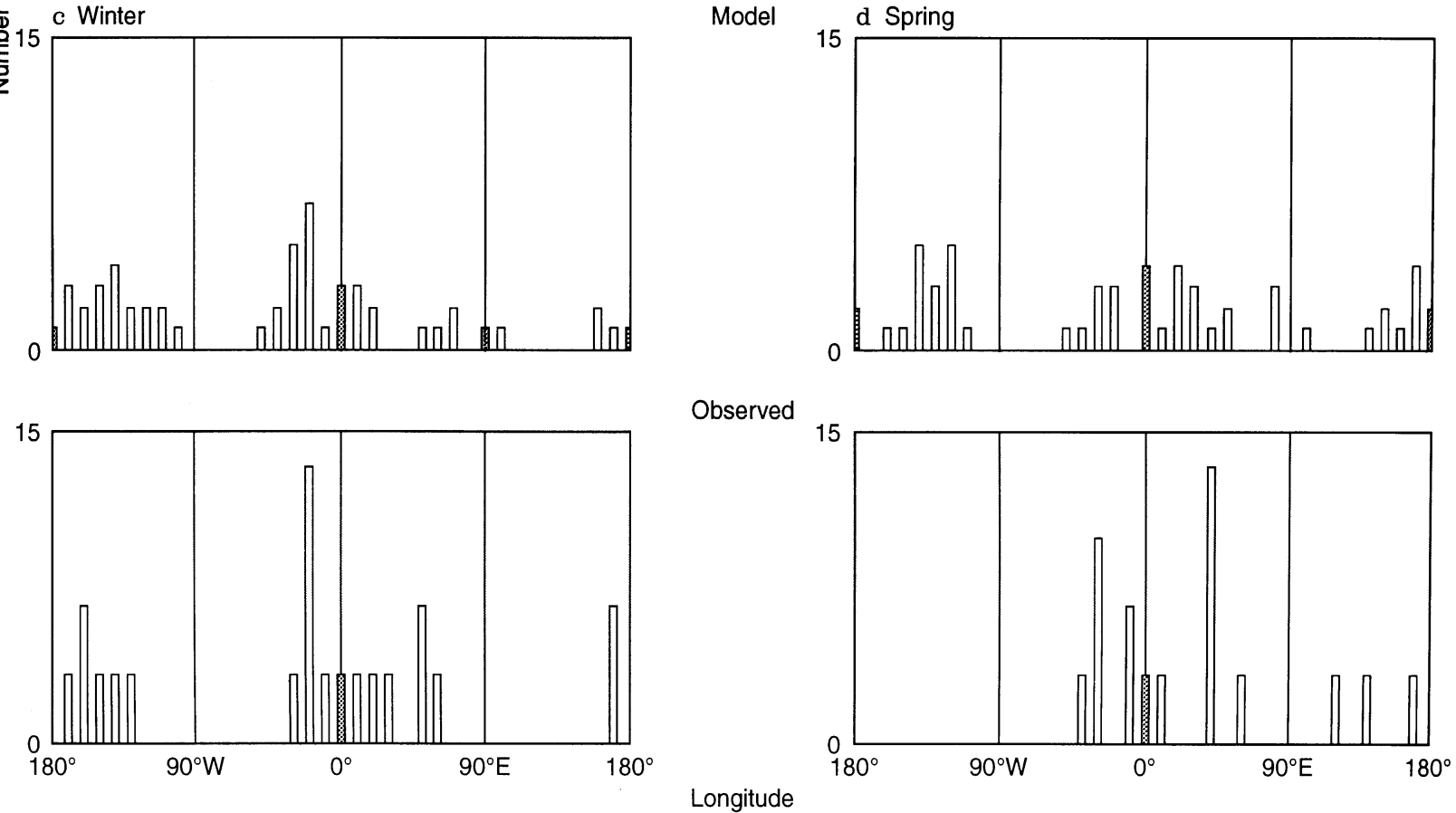

Fig. 2a-d. As in Fig. 1, except for the a summer $\mathbf{b}$ fall, $\mathbf{c}$ winter, and $\mathbf{d}$ spring seasons

$50^{\circ} \mathrm{W}$ and $10^{\circ} \mathrm{E}$. The second region was over Scandinavia, which is close to a summer formation region found by Triedl et al. (1981) found near $30^{\circ} \mathrm{E}$. Fewer summer season blocking events were found elsewhere in the Northern Hemisphere in both the model and observed climatologies. Winter season block formation regions (Fig. 2c) also compare favorably, especially over both oceanic regions. The CCM1 model captures the broad Pacific winter formation region, as well as the sharper maximum near $20^{\circ} \mathrm{W}$ over the Atlantic. Figure $2 \mathrm{~b}$, d shows that CCM1 correctly simulates the observed spring Atlantic block formation region, but exhibits a broader fall block formation region than was observed. Also, there were areas of frequent block formation found in the CCM1 climatology for the Pacific transition seasons that were not in the LS95a observations (which qualitatively agree with those of Triedl et al. 1981). Finally, in the Atlantic fall and winter, CCM1 places more blocking events farther to the west than are found in the observations.

Characteristics of model blocking anticyclones that compare favorably to observed blocking characteristics were the average annual occurrences (Table 1a) and 
Table 1. The average annual occurrence of blocking anticyclones in the control (330 ppm) simulation

\begin{tabular}{|c|c|c|c|c|c|}
\hline \multicolumn{6}{|c|}{ a Number of CS blocking events/ratio of CS to observed blocking events } \\
\hline Domain & Summer & Fall & Winter & Spring & Annual \\
\hline Atlantic & $1.7 / 2.53$ & $2.9 / 1.09$ & $2.4 / 0.80$ & $2.1 / 0.63$ & $9.1 / 0.94$ \\
\hline Pacific & $2.6 / 1.56$ & $2.4 / 1.80$ & $2.2 / 0.82$ & $2.5 / 3.73$ & $9.7 / 1.53$ \\
\hline Continental & $1.5 / 1.5$ & $0.7 / 0.53$ & $0.7 / 0.53$ & $0.7 / 0.53$ & $3.6 / 0.72$ \\
\hline All events & $5.8 / 1.74$ & $6.0 / 1.13$ & $5.3 / 0.76$ & $5.3 / 0.99$ & $22.4 / 1.06$ \\
\hline \multicolumn{6}{|c|}{ b Number of CS blocking days/ratio of CS to observed blocking days } \\
\hline Atlantic & $14.4 / 3.08$ & $20.1 / 1.01$ & $17.0 / 0.52$ & $18.3 / 0.63$ & $69.8 / 0.81$ \\
\hline Pacific & $17.7 / 1.48$ & $18.4 / 1.75$ & $13.4 / 0.58$ & $20.1 / 4.47$ & $69.6 / 1.39$ \\
\hline Continental & $12.7 / 1.56$ & $5.5 / 0.51$ & $4.5 / 0.40$ & $4.6 / 0.47$ & $27.3 / 0.63$ \\
\hline All events & $44.8 / 1.80$ & $44.0 / 0.99$ & $34.9 / 0.52$ & $43.0 / 0.99$ & $166.7 / 0.93$ \\
\hline
\end{tabular}

Table 2. Average half-wavelength $(\mathrm{km})$ of CCM1 blocking events by season and region

\begin{tabular}{|c|c|c|c|c|c|}
\hline \multirow[b]{2}{*}{ Domain } & \multicolumn{5}{|c|}{ Half-wavelength/ratio of $330 \mathrm{ppm}$ simulation events to observed events } \\
\hline & Summer & Fall & Winter & Spring & Annual \\
\hline Atlantic & $2360 / 0.91$ & $2593 / 0.80$ & $2895 / 0.84$ & $2684 / 0.85$ & $2650 / 0.81$ \\
\hline Pacific & $2594 / 0.91$ & $2627 / 1.10$ & $2855 / 1.11$ & $2522 / 1.08$ & $2643 / 1.02$ \\
\hline Continental & $2421 / 0.92$ & $2948 / 0.90$ & $2407 / 0.72$ & $2930 / 0.84$ & $2620 / 0.81$ \\
\hline All events & $2481 / 0.91$ & $2648 / 0.87$ & $2814 / 0.91$ & $2640 / 0.86$ & $2642 / 0.87$ \\
\hline
\end{tabular}

horizontal extent (Table 2). Table 1a displays the average annual occurrences of blocking anticyclones by region and season along with the ratio of CS to observed blocking events. LS95 demonstrated that in the Northern Hemisphere, blocking occurs an average of 21 times annually, which concurs with earlier results (e.g., Treidl et al. 1981; Lejenas and Okland 1983). Over the ten years of the control CCM1 simulation (CS), 224 events occurred, or 22.4 annually and testing the model annual mean against the mean of LS95 shows there was no statistically significant difference between them. However, as shown in Fig. 3a, the CCM1 blocking events were more uniformly distributed throughout the year instead of maximizing during the winter and minimizing during the late summer and early fall seasons as typically observed (Fig. 3b). Since the average annual number of blocking events was similar for both the CCM1 and observational climatologies, the weaker $500 \mathrm{hPa}$ height variance found in CCM1 implies that blocking events were, on the whole, weaker in CCM1. However, it should be cautioned that if blocking events were generally weaker in CCM1, it may not imply that blocking events are weaker within every region or season, and a more detailed analysis is made below.

In the CCM1 there were $6 \%$ and $28 \%$ fewer Atlantic (9.1 versus 9.7 per year) and Continental (3.6 versus 5.0) region blocking events, respectively, but over $50 \%$ more Pacific (9.7 versus 6.3) blocking events than observed overall. Examining these overall monthly PDF of the occurrences of CCM1 blocking events for the Atlantic region (Fig. 3 a, b) showed that the annual variation compared well, qualitatively, with the observed annual PDF in LS95. In the CS, there was a broad Atlantic winter maximum (from Oct-Apr) and a summer minimum. Pacific and Continental region blocking events in the CS exhibited exaggerated summer maxima in their overall frequency of occurrence when compared to observations. Also, in the Pacific there is no corresponding CS winter peak, or CS spring and fall minima to match those found
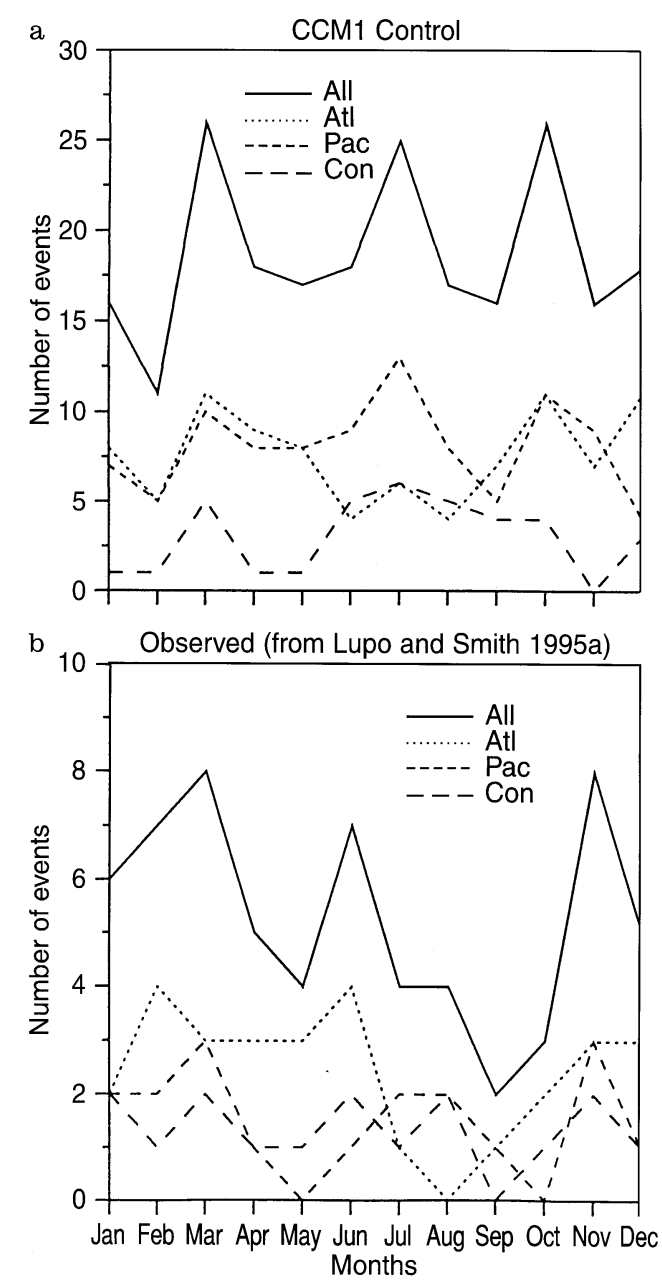

Fig. 3a, b. Total number of blocking anticyclones occurring in each month for a the control $(330 \mathrm{ppm})$ simulation, and b the observed climatology (data taken from Lupo and Smith 1995a) 
in the observed monthly PDFs. Finally, CS Continental region blocking maximized from Jun-Oct with comparatively few occurrences outside these months. This differed from the observational result that showed Continental region blocking to be uniformly distributed throughout the year.

Blocking events in the CCM1 climatology (Table 2) were generally smaller in area than those found observationally, and this result was found to be significant at the 99\% confidence level. Most of this difference between CS and observed events is accounted for by CS blocking events over the Atlantic region, which were significantly smaller than their observational counterparts. In the CCM1 climatology, Atlantic and Continental region blocks were about $19 \%$ smaller and occurred at an average of about $5^{\circ}$ latitude farther north than observed blocking events (not shown) which may partially account for the differences in size. The half-wavelength of Pacific region blocks compared more favorably to their observational counterparts. This is at least partially due to the fact that the model blocking anticyclones occurred at similar latitudes to those of observed events. An intraseasonal comparison of CCM1 blocking events for the entire sample and each individual region demonstrates that blocking events were larger in the winter than they were in the summer. This result agrees with the findings of LS95 who showed that this seasonal variance in size is partially related to a seasonal migration of blocking events and storm tracks southward (northward) for the winter (summer) months.

The duration (Fig. 4) of the CCM1 model blocking events compared less favorably to the observations than the characteristics already considered. The average duration of CCM1 blocks was less than the average duration of observed events overall (7.4 versus 8.6 days), over every region, and over every season except summer. A test of the sample means revealed that the smaller model mean duration was a result significant at the $99 \%$ confidence level. A further examination reveals that the durations were shortest in the fall and winter and longer during the spring and summer seasons. In the observed climatology of LS95, blocking events were more (less) persistent in the winter (summer). The average annual number of blocking days in the CCM1 climatology was $92 \%$ that of the observed (Table 1b). This difference may be partially attributable to the coarse resolution of the model, which may fail to capture sufficiently the contribution by the synoptic-scale in maintaining large-scale features, given the often highly non-linear interactions between the cyclone scale and blocking scale waves that appear to occur observationally. Also, it has been shown that CCM1 produces weaker storm track regions (e.g., Williamson and
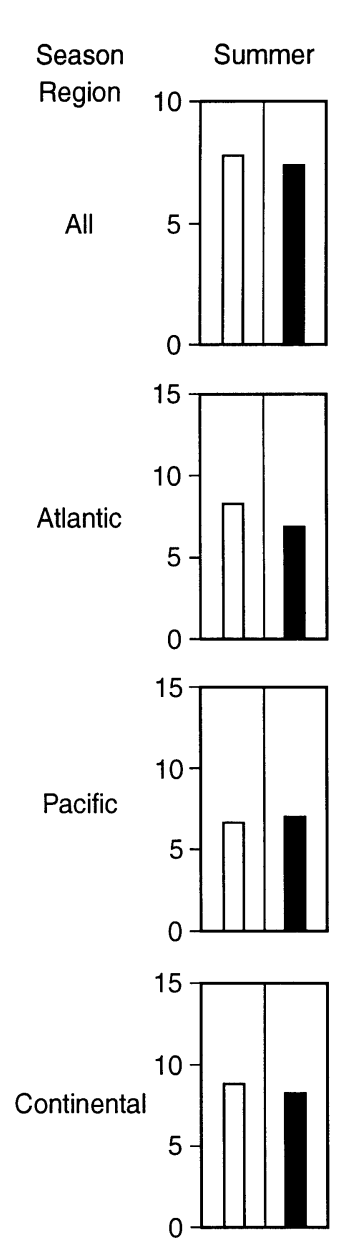

Average blocking anticyclone duration (days)

Fall Winter Spring
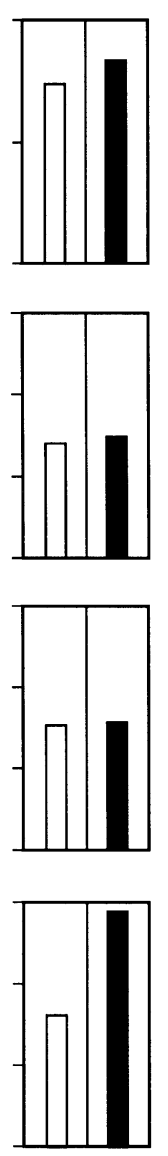
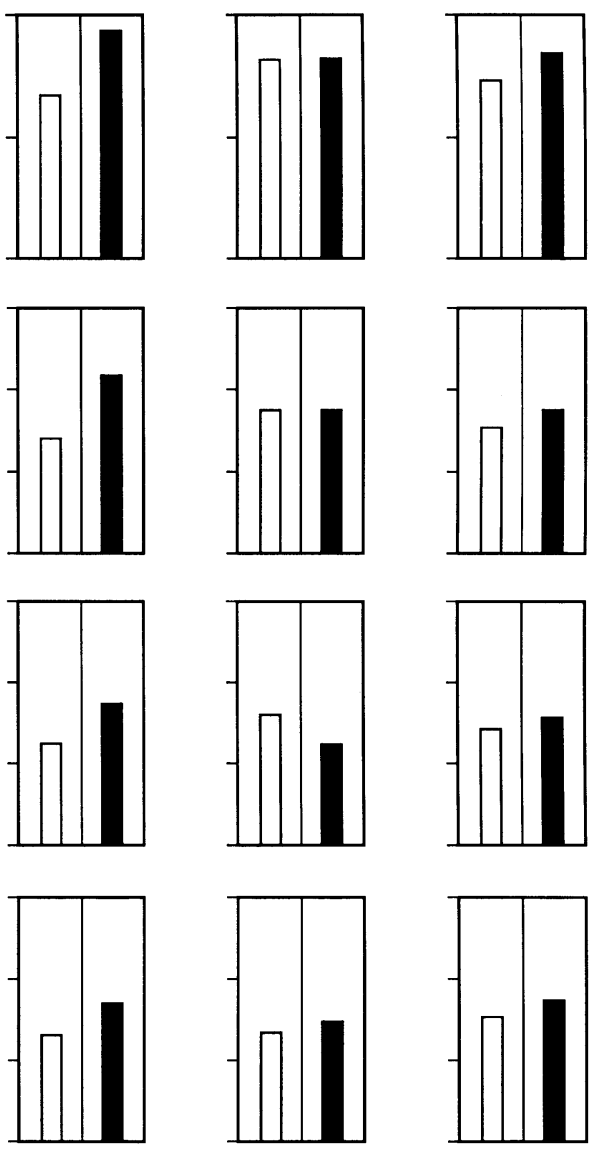

All

Fig. 4. Average durations of blocking anticyclones for the control (330 ppm) simulation and the observed climatology for the total samples, each region, and each season 
Table 3. Seasonal and regional averages of block intensity $(B I)$

\begin{tabular}{|c|c|c|c|c|c|}
\hline Domain & $\begin{array}{l}\text { Average } \\
\text { Summer }\end{array}$ & $\begin{array}{l}\text { vent inten } \\
\text { Fall }\end{array}$ & $\begin{array}{l}\text { CS to obs } \\
\text { Winter }\end{array}$ & Spring & Annual \\
\hline Atlantic & $2.2 / 0.83$ & $3.0 / 0.75$ & $3.2 / 0.74$ & $2.9 / 0.85$ & $2.9 / 0.76$ \\
\hline Pacific & $2.0 / 0.83$ & $3.1 / 0.76$ & $3.6 / 0.98$ & $2.4 / 1.11$ & $2.8 / 0.85$ \\
\hline Continental & $2.4 / 0.86$ & $3.2 / 0 / 76$ & $2.6 / 0.77$ & $2.3 / 0.66$ & $2.6 / 0.74$ \\
\hline All events & $2.2 / 0.86$ & $3.1 / 0.76$ & $3.3 / 0.85$ & $2.6 / 0.79$ & $2.8 / 0.78$ \\
\hline
\end{tabular}

Williamson 1987) as shown by the correlation of $u^{\prime}$ and $v^{\prime}$, which implies that the model produces fewer and/or weaker cyclones. Given the dynamic link between block formation and maintenance, and mid-latitude transients (e.g., Tsou and Smith 1990; Alberta et al. 1991; and many others), primarily through the advection of anticyclonic vorticity and/or low potential vorticity air into the blocked region, as well as the favorable comparison of block occurrences in CCM1 to observations, fewer cyclones in CCM1 would be a result consistent with CCM1 blocks that do not persist as long as their observed counterparts.

Blocking events in the CCM1 model climatology were significantly less intense than observed events (Table 3), and this result was also significant at the $99 \%$ confidence interval. Again, the difference is systematic, i.e., it occurs in every season for every region, with the exception of the spring season for the Pacific region. While the intensities of observed blocking events in LS95 were distributed nearly normal with respect to the mean, the PDF of CCM1 block intensities were skewed toward weaker values. In the CCM1 blocking climatology, $43.3 \%$ of all events were classified as weak $(<2.5)$. By comparison, only $14.2 \%$ of observed blocking events were classified as weak. An equal number of observed events were classified as strong ( $>4.5$ ), but only 7 of 224 (3.1\%) CCM1 blocking events could be classified similarly. All of these events occurred during the fall and winter months, which does agree with the observational climatology finding that the majority of strong blocking events occur in the fall and winter.

The average intensities of CCM1 blocking events were strongest during the winter months and weakest during the summer months for all regions. Atlantic blocks were stronger than those over either the Pacific or Continental regions. Both of these results were similar to the observational results of LS95. Also, the systematically weaker

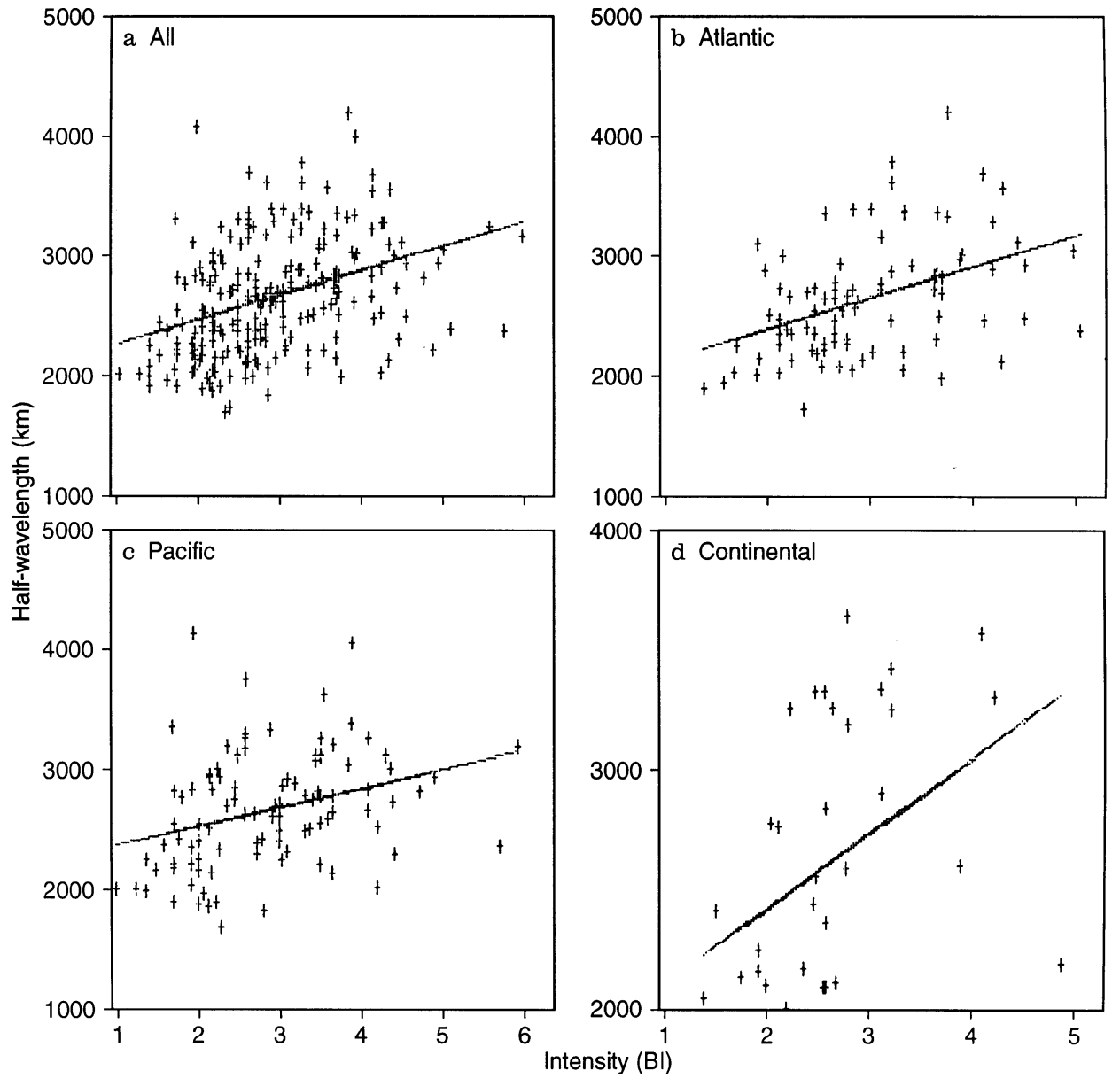

Fig. 5a-d. Scatter plots of blocking anticyclone intensities (abscissa) versus half-wavelength (ordinate) of the control $(330 \mathrm{ppm})$ simulation for the a total sample, b Atlantic, c Pacific, and d Continental regions 
CCM1 blocking events are consistent with the observation that the $500 \mathrm{hPa}$ height variance over the eastern oceanic regions is less than observed. This suggests there may be a difference between the amplitudes of wave modes involved in the life-cycles of CCM1 and observed blocking events. The results of Hansen and Sutera (1993a) suggest this difference may be distributed along all wave numbers.

Finally, as in LS95, each blocking characteristic was correlated to all the others in order to determine if any relationship existed among them. Only the block intensity and half-wavelength (size) demonstrated any significant relationship (Fig. 5), implying that a stronger block also tended to be larger in extent. A correlation of 0.377 was found between intensity and duration, a result found to be significant at the $99 \%$ confidence level. In testing each region, block intensity and size were again highly correlated for both the Atlantic and Pacific regions (significant at the $99 \%$ confidence level). Therefore, this result, in combination with the favorable (unfavorable) latitudinal positioning of Pacific (Atlantic) blocking anticyclones in CCM1 compared to observations, may explain the size difference between CCM1 model and observed blocks. No other significant relationships between the blocking characteristics were found, a result consistent with those of LS95.

\subsection{A comparison to Bates and Meehl (1986)}

As noted in the previous section, the comparison of our results to those of Bates and Meehl (1986) (hereafter, BM86) was made more direct by adjusting our definitions of season and block duration. Since the two methodologies applied are very different, only a few characteristics of Northern Hemisphere blocking anticyclones derived from our climatology, such as frequency of occurrence and location were directly comparable. A comparison of our regions of block formation (Fig. 2a, c) to their $500 \mathrm{hPa}$ persistent height anomalies (their Fig. 7) demonstrates the CCM1 summer and winter peak formation regions correspond well to similar regions of blocking activity found in CCM0B. Also, a comparison of the latitudinal positioning of Pacific region blocking events in association with Table 2 showed that observed and CCM1 events were located at similar latitudes. This result concurs with those of Bates and Meehl (1986) who show that their Pacific (and Continental) region events occur at similar latitudes to those observed by Shukla and Mo (1983). However, in our study, Atlantic and Continental region blocking events occurred poleward of those observed by LS95, while blocking events over the Atlantic ocean in BM86 occurred equatorward of those observed by Shukla and Mo (1983). This difference may at least partially be explained by the difference between the winter climates of CCM1 and CCM0B. It is also probable that the difference between the applied methodologies is also partly responsible.

A comparison of our CS block occurrences with those of Bates and Meehl (1986) (Fig. 6) demonstrates a difference in the overall annual variation of block occurrences between the two model climatologies. Figure 6 compares the average annual occurrences of blocking events found
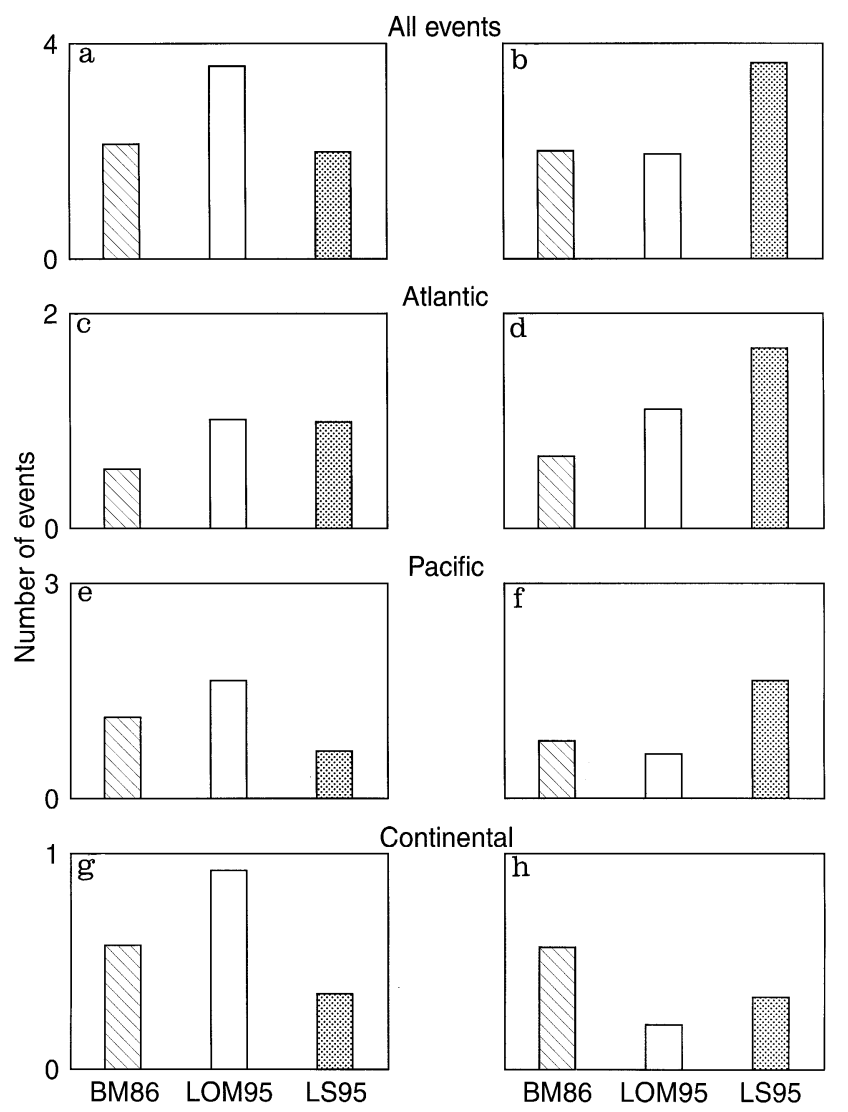

Fig. 6. Comparison between the annual mean summer and winter block occurrences from Bates and Meehl (1986) (BM86), our model climatology (LOM95), and the observed climatology of LS95 for a, b total samples, c, d Atlantic region, e, f Pacific region, $\mathbf{g}$, h Continental region

by BM86, LS95, and this study. The results are displayed as bar graphs. The BM86 climatology suggests that there is little annual variation in block occurrence in CCM0, while our climatology suggests there are more blocking events in the summer than in the winter (Fig. 6a, b). Both of these CCM model results contradict the observed results (e.g., Lejenas and Okland 1983; LS95) which show more blocking events occur during the winter season.

Stratifying the results of all three climatologies by region reveals that comparisons between our climatology and BM86 for the Atlantic region (Fig. 6c,d) show little qualitative agreement for the annual variation (i.e., blocking is only slightly more frequent in winter over the Atlantic), since both model climatologies underestimate the observed annual variation and frequency of occurrence. In general, Continental region (Fig. 6g, h) blocking events occurred more often than observed in both model studies, but the BM86 climatology shows little or no annual variation in the frequency of occurrence; which agreed better with observations than the results of this study. Over the Pacific region (Fig. 6e,f) block occurrences in both model climatologies are more (less) frequent in the summer (winter) than those in LS95, and both reversed the observed annual variation of block occurrence (i.e., more blocks occur in the winter months over the Pacific 
region). Unlike the results of the Atlantic region, the annual occurrence (sum of the summer and winter) blocking for this region corresponded well with the observed in this study. It has been shown that the $500 \mathrm{hPa}$ height variance is less than observed in both models. Therefore, as shown for our CCM1 climatology, individual Pacific blocking events should indeed be weaker in CCMOB than the observed if an analysis of CCMOB block intensities were performed. The paucity of block occurrences over the Pacific region in winter for the CCM1 model is also consistent with the apparent lack of an amplified wave number 2-4 (large-scale flow) regime in this model as noted by Hansen and Sutera (1993a). Hansen and Sutera (1993b) also found that most observed Pacific blocking events in winter are associated with such a large-scale flow regime.

\section{A comparison of the double $\mathrm{CO}_{2}$ simulation to the control climatology}

Figure 7 shows the histograms of block formation regions for the total five-year sample of $2 \times \mathrm{CO}_{2}$ blocking events
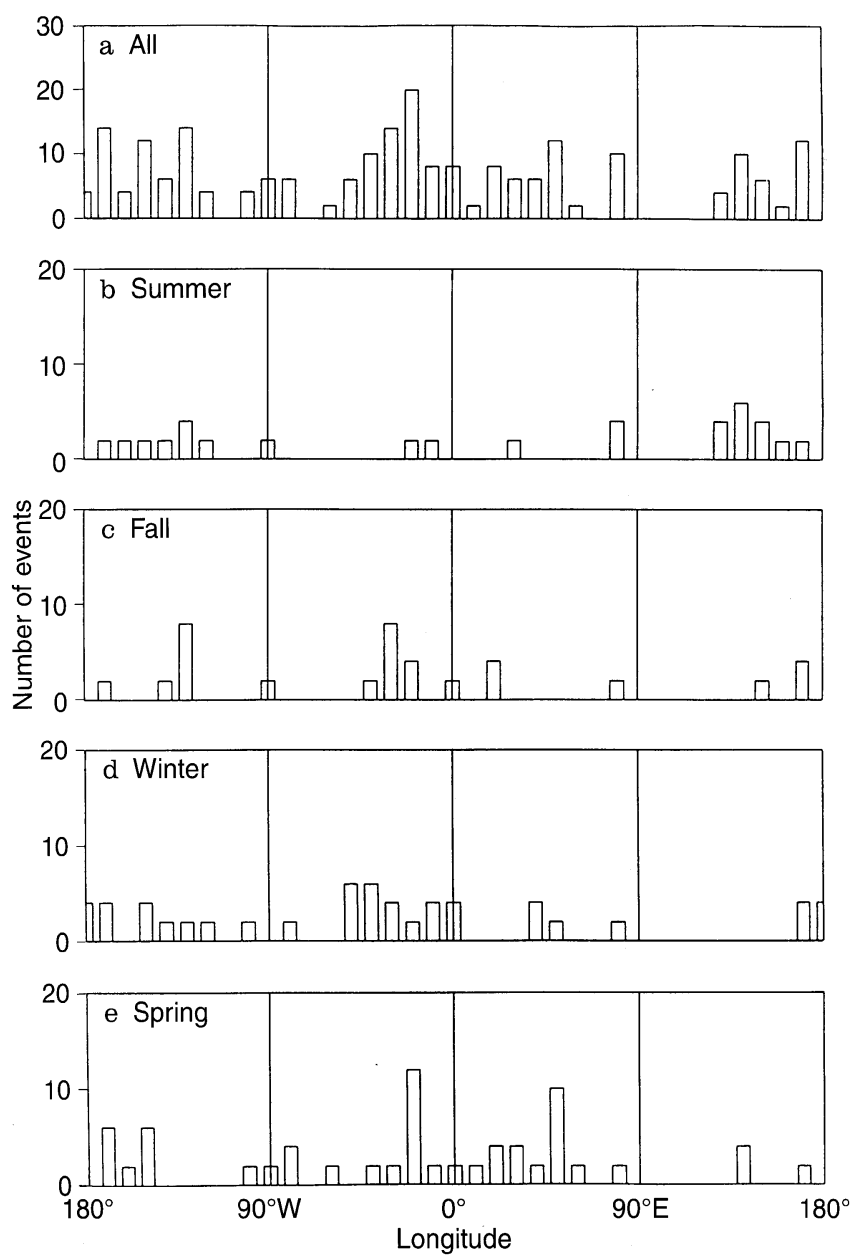

Fig. 7a-e. Number of blocking anticyclones forming in $10^{\circ}$ longitude basins for a 10-year period in the Northerm Hemisphere for the double $\mathrm{CO}_{2}$ experiment; a total sample, b summer, c fall, d winter, and e spring seasons and by season normalized to ten years so a direct comparison can be made with Figs. 1 and 2. The double $\mathrm{CO}_{2}$ simulation (DCS) model run (Fig. 7a) has a broad block formation region over the Pacific region, as well as a sharper peak in the Atlantic region, which is similar to the $\mathrm{CS}$ and observed climatologies. However, like the CS, this peak is located about one or two grid intervals west of the observed peak, and more blocking events are observed to form over the western and central Atlantic region. Unlike the CS, the DCS (Fig. 7a) does show the preferred region for block formation over the western Asian continent found observationally. Blocking events were also found over the North American continent in the DCS (Fig. 7), a feature that is conspicuously absent from both the CS and observational climatologies (see Fig. 1a,b). An intraseasonal examination reveals that the location of DCS fall and winter season events (Fig. 7c,d) compared favorably to the CS over both the Atlantic and Pacific region (Fig. 2b, c), but there was a noticeable paucity of fall season DCS blocks. An examination of the genesis locations (spring) DCS events (Fig. 7b, d) shows good qualitative agreement with the CS for the Pacific (Atlantic) region, but a lack of DCS Atlantic (Pacific) region blocking.

The total five-year DCS sample includes 111 events, or an average of 22.2 events per blocking year. The average annual frequency of occurrence in the DCS is strikingly similar to that in the CS. However, this does not preclude significant seasonal and/or regional changes in blocking activity. For example, the frequency of block occurrences over the continental region increased from 3.6 events annually in the CS to 5.8 in the DCS. Also, as was suggested by the previous example, "internal compensation" can take place in climatologies that have similar overall characteristics, and this necessitates a more detailed investigation.

In Fig. 8a (Table 4) the results are stratified by month (season). They reveal that DCS blocking events, unlike CS blocking events (Fig. 4a), showed a distinct maximum in occurrence during the spring and a minimum in the fall. While occurrence of Atlantic region blocking events are similar to those in the CS and observations, there were changes in the monthly frequency of block occurrences for both the Pacific and Continental region. In the DCS, there were fewer Pacific region blocking events than in the CS, and their seasonal PDF was more typical of observed continental events (i.e., no seasonal variation). For the continental region, the differences between the DCS and CS seasonal PDFs were more striking. In the DCS, there were almost twice as many events as in the CS, including more events over the North American continent. The occurrence of DCS blocking events within this region exhibited a pronounced spring (fall) maximum (minimum), which occurred slightly earlier in the calendar year than in the CS and whose impact on the total Northern Hemisphere occurrences is easily seen in Fig. 8a.

The total number of DCS blocks increased in the winter and spring, but decreased in the summer and fall when compared to the CS. The largest changes in Northern Hemisphere blocking frequency occurred in spring which showed a $43 \%$ increase (7.6 DCS versus 5.3 CS events per spring) in blocking activity. This change in frequency of occurrence was examined in terms of mean occurrences 

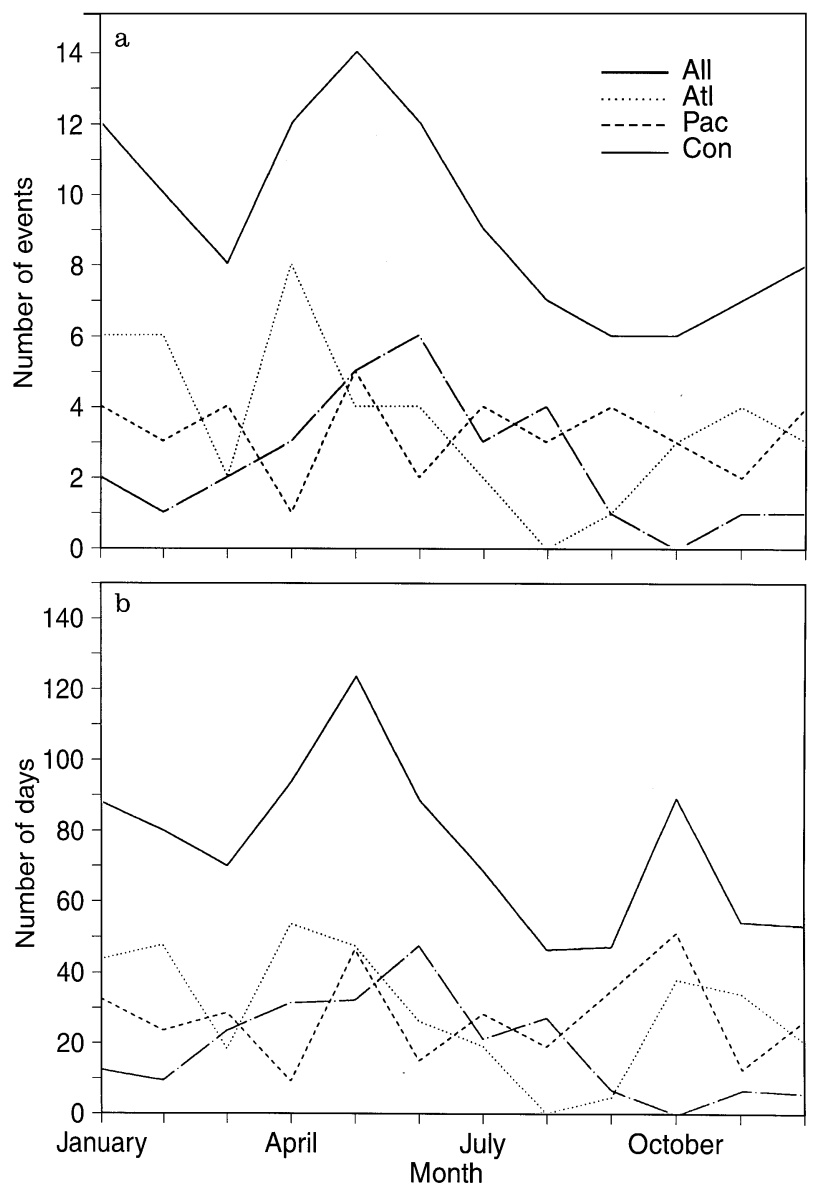

Fig. 8. a Total number of blocking anticyclone occurrences, and b blocking days for each month in the double $\mathrm{CO}_{2}$ experiment

per year, and the increase in spring occurrences proved to be significant (at 95\% confidence level). The large increase in spring blocking activity is mainly associated with a four-fold ( 2.8 versus 0.7 events annually) increase in the number of Continental region events. The number of
Atlantic region events also increased appreciably $(52 \%$ or 3.2 versus 2.1 events). The summer season decrease in block occurrence in the double $\mathrm{CO}_{2}$ experiment was due primarily to Atlantic region decreases $(65 \%$ or 0.6 versus 1.7 event annually). In the fall season, however, all three regions experienced a decrease in blocking activity.

While the overall frequency of block occurrences underwent no significant change, the number of blocking days and durations exhibited larger increases. In general, the average annual total number of days (Table 4) increased $7.6 \%$ for the DCS, however, this increase was not statistically significant. The continental region exhibited a large increase $(63 \%$ or 44.4 days versus 27.3 days per year), while both the Pacific and Atlantic regions exhibited a small decrease or no change in the annual number of days, respectively. The Pacific region showed a smaller decrease in the total number of blocking days than the decrease in the number of events, but the Continental region exhibited similar increases in the total number of blocking days and events. These changes were examined in terms of mean annual number of days, and only the increase in Continental region blocking days proved to be significant (at the 95\% confidence level). An intraseasonal examination shows that the number of summer and fall blocking events and total days were fewer, on the whole in the DCS, than those in the CS (32.2 days versus 44.8 days and 39 days versus 44.0 days per year, respectively). These decreases, however, were not statistically significant. By contrast, the number of winter and spring blocking events and total days exhibit increases (47 days versus 34.9 days and 61.2 days versus 43 days per year, respectively), and both increases significant at the $95 \%$ and $99 \%$ confidence level, respectively. The largest increase in the number of blocking days, like the largest increase in block occurrences, occurred over the continental regions in the spring (a more than four-fold increase), and, again, the impact of this increase is clearly evident in Fig. 9. It should also be noted that the number of blocking days increased in both the winter and spring seasons over every region, with the exception of the Pacific region spring which showed a decrease (Table $4 \mathrm{~b}$ ). The number of blocking days showed

Table 4. Seasonal and regional averages of the occurrence of DCS blocking events

\begin{tabular}{|c|c|c|c|c|c|}
\hline Domain & Summer & Fall & Winter & Spring & Annual \\
\hline \multicolumn{6}{|c|}{ a Average number of DCS events/ratio of $660 \mathrm{ppm}$ to $330 \mathrm{ppm}$ events } \\
\hline Atlantic & $0.6 / 0.35$ & $2.0 / 0.69$ & $2.8 / 1.17$ & $3.2 / 1.52$ & $8.6 / 0.95$ \\
\hline Pacific & $2.2 / 0.85$ & $1.8 / 0.75$ & $2.2 / 1.00$ & $1.6 / 0.64$ & $7.8 / 0.80$ \\
\hline Continental & $1.6 / 1.07$ & $0.4 / 0.57$ & $1.0 / 1.43$ & $2.8 / 4.00$ & $5.8 / 1.61$ \\
\hline All events & $4.4 / 0.76$ & $4.2 / 0.70$ & $6.0 / 1.13$ & $7.6 / 1.43$ & $22.2 / 0.99$ \\
\hline \multicolumn{6}{|c|}{$\mathrm{b}$ Average number of DCS blocking days/ratio $660 \mathrm{ppm}$ to $330 \mathrm{ppm}$ blocking days } \\
\hline Atlantic & $4.8 / 0.33$ & $18.2 / 0.91$ & 21.6/1.27 & $25.2 / 1.38$ & $69.8 / 1.00$ \\
\hline Pacific & $16.4 / 0.93$ & $18.2 / 0.99$ & $16.6 / 1.24$ & $14.0 / 0.70$ & $65.2 / 0.94$ \\
\hline Continental & $11.0 / 0.87$ & $2.6 / 0.47$ & $8.8 / 1.96$ & $22.0 / 4.78$ & $44.4 / 1.63$ \\
\hline All events & $32.2 / 0.72$ & $39.0 / 0.89$ & $47.0 / 1.35$ & $61.2 / 1.42$ & $179.4 / 1.08$ \\
\hline \multicolumn{6}{|c|}{ c Average duration (days) of DCS blocking events/ratio of $660 \mathrm{ppm}$ to $330 \mathrm{ppm}$ durations } \\
\hline Atlantic & $8.0 / 0.94$ & $9.1 / 1.32$ & $7.7 / 1.08$ & $7.9 / 0.91$ & $8.1 / 1.05$ \\
\hline Pacific & $7.5 / 1.10$ & $10.1 / 1.31$ & $7.5 / 1.23$ & $8.8 / 1.10$ & $8.4 / 1.17$ \\
\hline Continental & $6.9 / 0.81$ & $6.5 / 0.82$ & $8.8 / 1.38$ & $7.9 / 1.20$ & $7.7 / 1.01$ \\
\hline All events & $7.3 / 0.95$ & $9.3 / 1.27$ & $7.8 / 1.18$ & $8.1 / 1.00$ & $8.1 / 1.09$ \\
\hline
\end{tabular}



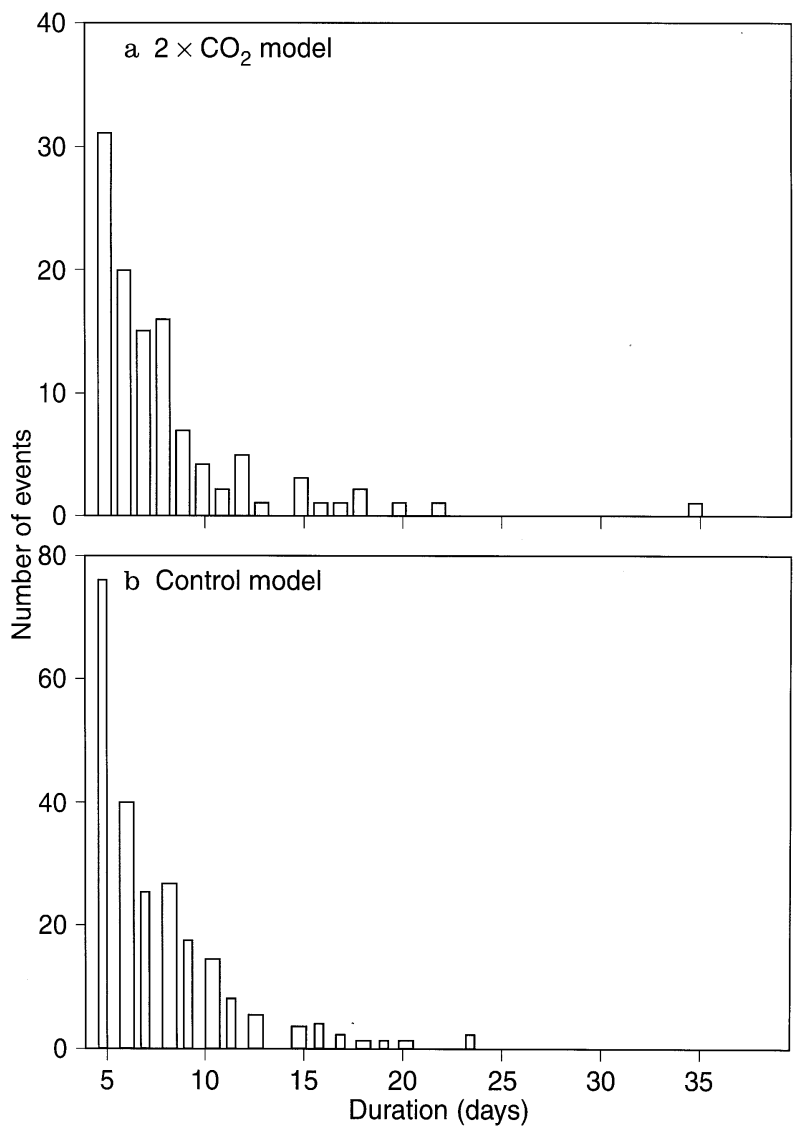

Fig. 9a, b. Durations (days) of all blocking anticyclones from the a double $\mathrm{CO}_{2}$, and b control (330 ppm) climatology

a decrease for both the summer and fall over all regions (Table 4b).

In the DCS, block durations experienced a $9.4 \%$ increase overall (significant at 99\%) and these durations were greater for most seasons and regions (Table 4c), with only the summer season showed modest or insignificant decreases. Increases in Pacific regional and winter seasonal mean durations were significant at the $95 \%$ confidence level. The largest seasonal or regional increase in block persistence occurred in the fall season, and was largely due to increases in Atlantic and Pacific region durations. However, this increased fall season persistence was not proven to be a significant increase. Aside from the fact that the sample size in that season was small, two of the three most persistent events in the DCS climatology occurred during that season.

Block intensities in the DCS (Table 5) were weaker for the five-year sample and for most regions and seasons when compared to the CS. The decrease in the overall mean block intensity was significant at the $95 \%$ confidence level. Exceptions occur, e.g., weak intensification of winter and spring Continental or fall Atlantic region blocking events. The largest overall decrease in mean intensity occurred for summer blocking events (significant at the $99 \%$ confidence level), which was largely due to the $20 \%$ decrease in intensity of summer Continental region blocking events. All other DCS seasons experienced similar decreases in intensity (approximately 5\%), with only the decrease in intensity of winter blocking events being significant at the $95 \%$ confidence level. There were also decreases in the intensity of blocking events across all regions. Additionally, the overall intensity difference between the DCS and CS was less than the intensity difference between the CS and observations of LS95.

The largest overall regional intensity difference occurs when comparing DCS and CS Pacific region events $(9 \%$ or $2.76 \%$ in the DCS versus 2.52 for the CS), and this was the only region to experience a significant (at the $99 \%$ confidence level) decrease in mean block intensity. Three particular subsets that showed the greatest weakening block intensities were summer season Atlantic and Continental, and winter season Pacific region blocking events. The PDF of blocking events (not shown) in the DCS, like CS events, is skewed toward weaker events, and 55.9\% (62 events) of all events were classified as weak. No events in the DCS could be classified as strong. While the actual intensities were generally weaker, the annual intensity trends are similar to those of both the CS and of observations, i.e., that blocking events were weaker in the summer and stronger in the winter. Finally, cross-correlating each blocking characteristic with one another produced the same result as the CS and observed blocking events in LS95 (i.e., only block size correlated positively with block intensity).

Blocking events in the DCS climatology were, in general, of similar size to those in the CS (Table 5b). A regional analysis shows that, like blocking events in the CS

Table 5. Seasonal and regional averages of block intensity $(B I)$ and size for the DCS

\begin{tabular}{|c|c|c|c|c|c|}
\hline Domain & Summer & Fall & Winter & Spring & Annual \\
\hline \multicolumn{6}{|c|}{ a DCS block intensity/ratio of $600 \mathrm{ppm}$ to $330 \mathrm{ppm}$ intensities } \\
\hline Atlantic & $1.8 / 0.82$ & $3.1 / 1.04$ & $3.2 / 0.99$ & $2.4 / 0.83$ & $2.8 / 0.97$ \\
\hline Pacific & $2.0 / 1.00$ & $2.8 / 0.89$ & $3.0 / 0.80$ & $2.4 / 0.97$ & $2.5 / 0.91$ \\
\hline Continental & $1.9 / 0.80$ & $2.9 / 0.90$ & $3.3 / 1.24$ & $2.6 / 1.10$ & $2.5 / 0.98$ \\
\hline All events & $1.9 / 0.89$ & $3.0 / 0.96$ & $3.1 / 0.94$ & $2.5 / 0.95$ & $2.6 / 0.95$ \\
\hline \multicolumn{6}{|c|}{ b DCS block sizes $(\mathrm{km}) /$ ratio of $600 \mathrm{ppm}$ to $330 \mathrm{ppm}$ half-wavelengths } \\
\hline Atlantic & $2147 / 0.91$ & $2736 / 1.06$ & $2810 / 0.97$ & $2582 / 0.96$ & $2659 / 1.00$ \\
\hline Pacific & $2691 / 1.04$ & $2560 / 0.97$ & $2790 / 0.98$ & $2824 / 1.12$ & $2717 / 1.03$ \\
\hline Continental & $2600 / 1.07$ & $2340 / 0.79$ & $3137 / 1.30$ & $2730 / 0.93$ & $2738 / 1.05$ \\
\hline All events & $2584 / 1.04$ & $2623 / 0.99$ & $2857 / 1.02$ & $2689 / 1.02$ & $2701 / 1.02$ \\
\hline
\end{tabular}


and unlike observed blocking events, blocking events in all three regions are also of similar size. Also, no region or season exhibited any significant change in block size when comparing CS and DCS blocking events. Examining the annual variation in DCS blocking anticyclone sizes shows that, like both CS and observed blocking events, they are largest during the winter season and smallest during the summer. There was a similar annual variation in block size found across all regions. Both Atlantic and Pacific regional block sizes were similar to their CS counterparts over all seasons. Continental region blocking events, however, were larger in the summer seasons and smaller during the transition seasons. Within the winter season, blocking events over both oceans were smaller and had a tendency to be located about $5^{\circ}$ latitude north of those in the CS. This result may be, at least in part, due to the northward retreat of the sea-ice margins over both northern oceans that has been found to occur in CCM1 within an increased $\mathrm{CO}_{2}$ atmosphere (Oglesby and Saltzman 1992).

\section{Summary and conclusions}

Two climatologies of Northern Hemisphere blocking anticyclones were derived from data output by the NCAR CCM1. These experiments included a present-day control simulation and a double present day $\mathrm{CO}_{2}$ concentration simulation (see Oglesby and Saltzman 1992, for more detail). The climatologies from both were developed using the methodology of Lupo and Smith (1995a), with the exception that relationships between the characteristics of blocking anticyclones and mid-latitude cyclones were not examined in detail here. The objectives of this study were to evaluate the ability of the CCM1 to reproduce the observed blocking climatology of the Northern Hemisphere, and to examine the possible impact of increased $\mathrm{CO}_{2}$ concentrations, and the implied "greenhouse" global warming, on the blocking climatology. In evaluating the performance of the control CCM1 experiment, the results were compared to the observational results of Lupo and Smith (1995a). Additionally, the results were compared to those of Bates and Meehl (1986) to determine what effect, if any, improvements made by the earlier versions of CCM (CCMOB) had on the climatology of blocking anticyclones.

The results show that the model did an adequate job in reproducing the climatology of blocking anticyclones in the Northern Hemisphere. The annual number of occurrences and the annual variations in block size and intensity were characteristics represented well by the model. A correlation, significant at the $99 \%$ confidence level, between the size and intensity of model blocks was found, a result also found by LS95 for the observations. Also, in general, the location of block genesis regions compared favorably with those of the observed climatology, especially over the Pacific region. Differences between the two climatologies in block genesis location for the Atlantic region may be attributable in part to the lack of oceanic dynamics in the model and the subsequent impact on the simulated North Atlantic cyclone track. Finally, the interannual variability of block occurrences was not exam- ined in this work owing to the short length of the model climatology and the fact that climatic variability in the 2-8 year range tied to the ENSO cycle and blocking would not be expected to exhibit a robust signal in this version of CCM1.

The results of this climatology using CCM1 were comparable to those of Bates and Meehl (1986) who used CCM0B. The only noteworthy difference, the latitudinal positioning of Atlantic blocking events, is probably due to the differences in each model's winter climatology. Therefore, the improvements made to the CCM did not significantly degrade the generally favorable comparison of the CCM0B model climatology with observations for blocking characteristics examined here. It is also important to note that no unified definition of blocking exists, and there are some fundamental differences between definitions used in various studies (e.g., Rex 1950; Obukhov et al. 1984; Shukla and Mo 1983; Lejenas and Okland 1983; Liu 1994; Mokhov et al. 1994). These differences could make comparisons between climatologies difficult. In particular, meridional, or Rex-type blocking events could be underestimated using our methodology.

A more detailed comparison of the model blocking climatology to the observed blocking climatology revealed some important differences. In general, model blocks were weaker and did not persist as long as their observational counterparts. Also, there was little annual variation in the occurrence of blocking events. This differs from observations which generally exhibit a pronounced winter maximum and summer minimum in block occurrence. This result can be explained by the greater number of spring and summer model events found over the Pacific region. The model also failed to adequately represent the occurrence of Continental region events. This failure may be at least partially attributed tot the failure of the model to adequately represent the Mediterranean area storm track.

The results of the double present-day $\mathrm{CO}_{2}$ concentration experiment showed that, in general, blocking anticyclones were more persistent but weaker than their counterparts in the control experiment. All other characteristics of the overall sample such as; frequency of occurrence, size, preferred genesis locations, and annual variations in size and intensity, were generally similar to the control experiment. The correlation between block size and intensity found in the control experiment and observations was also found in the $2 \times \mathrm{CO}_{2}$ case. A regional and seasonal analysis showed that there were some significant differences between the two climatologies, and perhaps the most striking difference was the three-fold or more increase in Continental region block occurrences and total block days. This increase is due to the appearance of the observed western Asian Continental maximum in the double $\mathrm{CO}_{2}$ run. There was also an increase in blocking frequency over the North American continent compared to the CS and observations, a result that was conspicuously absent from the control and observed climatologies. Additionally, there were more winter and spring blocking events in the DCS than in the CS, with the significant increase winter season and Pacific region block durations. There were fewer summer and fall DCS than CS blocking events, however, these DCS events were, in general, more persistent than their CS counterparts. 
In general, some differences were found between the characteristics of blocking anticyclones in the DCS versus those of the CS, especially over the continental regions. This does not imply, however, that these changes in the blocking climatology found here are occurring or will actually occur in observational blocking climatologies, as these changes are only valid for the climate of "planet" CCM1. Therefore, conclusions about changes in the blocking climatology found here should be examined in light of differences known to exist between that of CCM1 and observations. For example, it is now believed that the neglect of sulfates and other trace constituents that impact on the planetary albedo may be one reason why climatic trends in increased $\mathrm{CO}_{2}$ GCM experiments do not necessarily agree with observed climatic trends. Erickson et al. (1995) evaluated the indirect effect of sulfate aerosols on the CCM1 climate. Shaw (1995) shows that the build up of pollutants in Arctic regions could influence climate change. Iversen and Joranger (1985) show that blocking could play a role in the transport and build up of trace constituents, which could in turn feed back on the climatological behavior of synoptic-scale weather systems (Serreze et al. 1993) and larger scale systems such as blocking. Finally, in order to verify these conclusions about changes in $\mathrm{CO}_{2}$ concentration, similar climatologies for other values of $\mathrm{CO}_{2}$ could be compiled using the data of Oglesby and Saltzman (1992), who simulated several CCM1 climates using a range of $\mathrm{CO}_{2}$ concentrations.

Acknowledgements. The authors would like to acknowledge Dr. Gerald Meehl for stimulating the writing of this manuscript, and Dr. Anthony R. Hansen for his helpful comments. This research has been supported by a grant from the IBM Environmental Research Program, Dr. Joseph Sarsenski, Program Manager, under grant NAG8-915 from the National Aeronautics and Space Administration, and under grant 96-05-64571 from the Russian Foundation of Fundamental Investigators (RFFI).

\section{References}

Agayan GM, Mokhov II (1989) Quasistationary autumn regimes of the Northern Hemisphere atmosphere in FGGE. Atmos Oc Phys $25: 1150-1156$

Alberta TL, Colucci SJ, Davenport JC (1991) Rapid 500 mb cyclogenesis and anticyclogenesis. Mon Weather Rev 119:1186-1204

Bates GT, Meehl GA (1986) The effect of CO2 concentration on the frequency of blocking in a general circulation model coupled to a single mixed layer ocean model. Mon Weather Rev 114:687-701

Blackmon ML (1986) Building, testing, and using a GCM. Math Phys Sci 190C: $1-67$

Chen T-C, Tribbia JJ (1993) An effect of the models horizontal resolution on stationary eddies simulated by the NCAR CCM1. J Clim 6:1657-1664

Colucci SJ (1985) Explosive cyclogenesis and large scale circulation changes: implications for atmospheric blocking. J Atmos Sci $42: 2701-2717$

Colucci SJ (1987) Comparative diagnosis of blocking versus nonblocking planetary scale circulation changes during synopticscale cyclogenesis. J Atmos Sci 44:124-139

Covey C, Thompson SL (1989) Testing the effects of ocean heat transport on climate. Paleogeog Paleoclim Paleoecol 75:331-341

Erickson DJ III, Oglesby RJ, Marshall S (1995) Climate response to indirect anthropogenic sulfate forcing. Geophys Res Let $22: 2017-2020$
Hansen AR (1986) Observational characteristics of atmospheric planetary waves with bimodal amplitude distributions. Adv Geophys $29: 101-133$

Hansen AR, Sutera A (1993a) Transient eddies and low frequency variability in the Northern Hemisphere winter climates of two GCMs. Proc Seventeenth Stanstead Seminar: 84-89

Hansen AR, Sutera A (1993b) A comparison between planetarywave flow regimes and blocking. Tellus $35 \mathrm{~A}: 281-288$

Held IM (1993) Large-scale dynamics and global warming. Bull Am Meteorol Soc 74:228-241

Hovmoller E (1949) The trough-and-ridge diagram. Tellus 1:62-67

Iversen T, Joranger E (1985) Arctic air pollution and large-scale atmospheric flows. Atmos Environ 19:2099-2108

Kiehl JT, Wolski RJ, Briegleb PG, Ramanathan V (1987) Documentation of radiation and cloud routines in the NCAR Community Climate Model. NCAR Note NCAR/TN-288 + IA. National Center for Atmospheric Research, Boulder, CO 80303

Lejenas H, Madden RA (1992) Traveling planetary-scale waves and blocking. Mon Weather Rev 120:2821-2830

Lejenas H, Okland H (1983) Characteristics of Northern Hemisphere blocking as determined from long time series of observational data. Tellus $35 \mathrm{~A}: 350-362$.

Liu Q (1994) On the definition and persistence of blocking. Tellus $46 \mathrm{~A}: 286-298$

Lupo AR, Smith PJ (1995a) Climatological features of blocking anticyclones in the Northern Hemisphere. Tellus 47A:439-456

Lupo AR, Smith PJ (1995b) Planetary and synoptic-scale interactions during the life cycle of a mid-latitude blocking anticyclone over the north Atlantic. Tellus 47A: Tellus Special Issue: The life cycles of extratropical cyclones 575-596

Mak M, Cai M (1989) Local barotropic instability. J Atmos Sci $46: 3289-3311$.

Mokhov II (1993) Diagnostics of the climate system structure. Gidrometeoizdat (in Russian) : St. Petersburg, Russia

Mokhov II, Doronina TN, Gryanik VM, Khairullin RR, Korovkina LV, Lagun VE, Mokhov OI, Naumov EP, Petukhov VK, Senatorsky AO, Tevs MV (1994) Extratropical cyclones and anticyclones: tendencies of change. Proc Symp. The life cycles of extratropical cyclones, vol II (27 June-1 July 1994, Bergen, Norway): $56-60$

Neter J, Wasserman W, Whitmore GA (1988) Applied statistics, 3rd edn. Allyn and Bacon, Boston, MA

Obukhov AM, Kurgansky MV, Tatarskaya MS (1984) Dynamical conditions for the origin of droughts and other large-scale weather anomalies. Metéorol Hydrol 10:5-13

Oglesby RJ, Saltzman B (1992) Equilibrium climate statistics of a general circulation model as a function of atmospheric carbondioxide. Part I: geographical distributions of primary variables. J Clim 5: 66-92

Oglesby RJ, Maasch KA, Saltzman B (1989) Glacial meltwater cooling of the Gulf of Mexico: GCM implications for Holocene and present-day climates. Clim Dyn 3:115-133

Phillips N (1957) A coordinate system having some special advantages for numerical forecasting. J Meteorol 14:184-185

Quiroz RS (1987) The association of stratospheric warming with tropospheric blocking. J Geophys Res 91:5277-5285

Rex DF (1950) Blocking action in the middle troposphere and its effect on regional climate II. The climatology of blocking action. Tellus 2:275-301

Semtner AJ (1976) A model for the thermodynamic growth of sea-ice in numerical simulations of climate. J Phys Oc 6:370-389

Serreze MC, Box JE, Barry RG, Walsh JE (1993) Characteristics of Arctic synoptic activity, 1952-1989. Meteorol Atmos Phys $51: 147-164$

Shaw GE (1995) The Arctic haze phenomenon. Bull Am Meteorol Soc 76:2403-2413

Shukla J, Mo KC (1983) Seasonal and geographical variation of blocking. Mon Weather Rev 111:388-402

Stewart DA (1994) Predictability of low-frequency planetary waves in a simple low resolution model. Mon Weather Rev 122: 405-423 
Tibaldi S (1993) Low-frequency variability and blocking as diagnostic tools for global climate models. Proc NATO Advanced Research Workshop on Prediction of Interannual Climate Variations NATO-AS1: 173-182

Tibaldi S, Tosi E, Navarra A, Pedulli L (1994) Northern and Southern Hemisphere seasonal variability of blocking fre quency and predictability. Mon Weather Rev 122: 1971-2003

Triedl RA, Birch EC, Sajecki P (1981) Blocking action in the Northern Hemisphere: a climatological study. Atmos Ocean 19: $1-23$

Tsou C-H, Smith PJ (1990) The role of synoptic/planetary-scale interactions during the development of a blocking anticyclone. Tellus 42A: 174-193
Whittaker LM, Horn LH (1982) Atlas of Northern Hemisphere extratropical cyclone activity 1958-1977. Department of Meteorology, University of Wisconsin, Madison, WI 53706, USA

Wiin-Nielsen AC (1986) Global scale circulations - a review. Adv Geophys 29:3-30

Williamson GS, Williamson DL (1987) Circulation statistics from seasonal and perpetual January and July simulations with the NCAR Community Climate Model (CCM1): R15. NCAR Tech Note NCAR/TN-302 + STR. National Center for Atmospheric Research, Boulder, CO 80303

Williamson DL, Kiehl JT, Ramanathan V, Dickenson RE, Hack JJ (1987) Description of the NCAR Community Climate Model. NCAR Tech Note NCAR/TN-302 + STR. National Center for Atmospheric Research, Boulder, CO 80303 